LA- $-10138-M S$

DE85 005235

\title{
Thirty-Five Years of Drift-Tube Linac Experience
}

H. B. Knowles

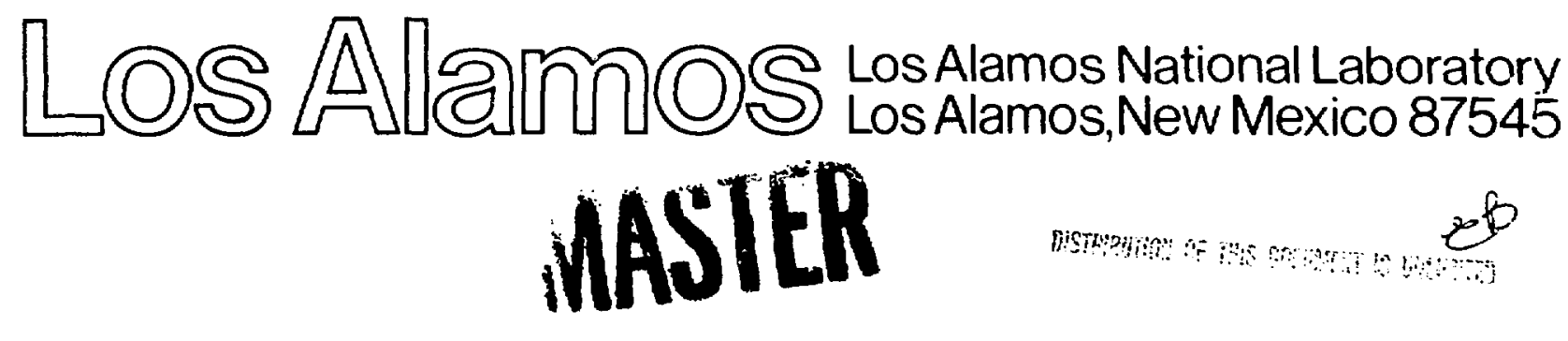




\section{DISCLAIMER}

This report was prepared as an account of work sponsored by an agency of the United States Government. Neither the United States Government ner any agency thereof, nor any of their employees, makes any warranty, express or implier, or assumes any legal liability or responsibility for the accuracy, completeness, or usefulness of any information, apparatus, product, or process disclosed, or represents that its use would not infringe privately owned rights. Referen. : herein to any specific commercial product, process, or service by trade name, trademark, manufacturer, or otherwise does not necessarily constitute or imply its endorsement, recommendation, or favoring by the United States Government or any agency thereof. The views and opinions of authors expressed herein de not necessarily state or reflect those of the United States Government or any agency thereof. 


\title{
THIRTY-FIVE YEARS OF DRIFT-TUBE LINAC EXPERIENCE
}

by

\author{
H. B. Knowles
}

\begin{abstract}
The history of the drift-tube linear accelerator (linac) for the first 35 years of its existence is briefly reviewed. Both US and foreign experience is included. Particular attention is given to technological improvements, operational reliability, capital investment, and number of personnel committed to drift-tube linac (DTL) development. Preliminary data indicate that second- and third-generation (post-1960) DTLs have, in the US alone, operated for a combined total period of more than 75 machine-years and that very high reliability (>90\%) has been achicved. Existing US drift-tube linacs represent a capital investment of at least \$250 million (1983). Additional statistical evidence, derived from the proceedings of the last 11 linear accelerator conferences, supports the view that the DTL has achieved a mature technological base. The report concludes with a discussion of important recent advances in technology and their applications to the fourth generation of DrLs, many of which are now becoming operational.
\end{abstract}

\section{INTRODUCTION}

It is a little too late to celebrate the fiftieth anniversary of the drift-tube linac (DTL) concept, because Wideröe's original publication on the subject appeared in $1928 .{ }^{1}$ However, most examples of the modern DTL are derived from the prototype pioneered by Alvarez and his associates at the facility now known as Lawrence Berkeley Laboratory (LBL). The first report on the operation of the 32-MeV proton linear accelerator was an internal University of California Radiation Laboratory (UCRL) report of $1948 .^{2}$

Therefore, a valid claim for three-and-a-half decades of DTL experience can be made. Indeed, the terms "drifttube linac" and "Alvarez linac" would be exactly synonymous, if it were not for the several recent revivals of the Wilderöe concept, which is still alive and well. The Alvarez linac will be the primary subject of discussion in this review document, however.
When starting even a cursory survey of DTL history, there is a strong temptation to intermingle it with the contemporary and parallel history of the electron linear accelerator. The two types of particle accelerator have almost simultaneous origins: the first report on a (standing-wave) electron accelerator was published in 1948 by Slater and his coworkers. ${ }^{3}$ Many examples of technologica! interchange between these twc related but distinct branches of accelerator science can be cited. In addition, the history of electron linacs might be invoked, simply on the basis of the very large number of such linacs now in service, to support any claims concerning experience with the general family of linear accelerators. Electron machines are, of course, much more numerous than DTLs because electron linacs are so useful in medical and industrial applicaticns and are less expensive than DTLs.

It has nevertheless been decided that, for the purpose of this preliminary survey report, attention will be 
directed to the DTL alone. The DTL is required to perform certain functions that are not common to any other accelerator-in particular, to control and accelerate intense beams of low-velocity ions-and, if only for that reason, its uniqueness can be defended.

\section{FIRST-GENERATION DRIFT-TUBE LINACS}

"First-generation" is defined here to mean that the DTL had two specific features.

- Grid Focusing: Earnshaw's theorem explicitly denies the possibility of having both phase-stable and radially stable beams simultaneously, in the absence of magnetic fields. Because the first DTL was designed to operate, essentially, in an electrostatic mode, it was necessary to distort the elestric field at the entrance to each drift tube with a doublehyperbolic grid.* The grids provided the necessary radial focusing, but at severe costs in beam intensity. Although each grid intercepted only a small percentage of the beam, the curnulative effect of many grids became enormous.

- Separate Radio-Frequency (rf) Liner: The technology of the early period could not produce a material of sufficient mechanical strength to contain the required vacuum inside the DTL, which at the same time acted as a good conductor of rf currents. Consequently, an exterior steel vacuum tank was constructed to house an internally supported copper if liner. The liner was fabricated of thin $(\simeq 0.080$-in.) metal in a polygonal shape that approximated a circular cylinder. When the liner was heated by the if currents (together with other heat sources, such as the afternoon sun falling on the cooling tower), the flat planes of the liner were subject to abrupt expansion in random directions that led to local cavity detuning and, thus, occasionally, to unacceptable changes in output particle energy. ${ }^{4}$ Several other features of the first-generation DTL arose from its peculiar construction. A large, gassy surface area had to be pumped out through a high pumping impedance, and an oil diffusion pump had to be used. Even with liquidnitrogen trapping on the pump, the pressure could

*The original plan was to provide grid focusing by placing very thin beryllium foils over all the drift-tube entrances. These are said to have survived about two minutes of beam before disappearing, as vapor, into the vacuum purmp. never be reduced below a few times $10^{-6}$ torr. The inner surfaces of the DTL were quite "dirty" by modern standards, and the accelerator was therefore subject to spark breakdown. Even without audible breakdown, there was a high external radiation field of $x$ rays. ${ }^{2}$ The $x$-ray radiation hazard near the accsierator was augmented by the neutrons produced when protons intercepted the beam-focusing grids at the entrance of each drift tube.

A different, but originally quite serious, problem was that of the if power amplifiers. The $32-\mathrm{MeV}$ Berkeley DTL was at first designed to be energized by a large number of low-power war-surplus amplifiers. These amplifiers were very unreliable, and constant replacement of the amplifier units became the principal occupation of the accelerator operating crew.* This rundamental problem eventually was solved by the development of a single high-power tetrode ri amplifier, which could operate at the design frequency of $202.5 \mathrm{MHz}$.**

In spite of its many drawbacks, this first DTL was the prototype of a number of immediate descendents, both in the United States and abroad. The Berkeley DTL was (at leest in part) developed to overcome the energy limitation ( $\sim 12 \mathrm{MeV}$ for protons) on the "conventional" cyclotron. (This limitation is often attributed to relativistic mass increase, although phase stability is an equally restrictive consid r ration.) Two other proton DTLs were built very soor the Berkeley prototype went into service. One was the $68-\mathrm{MeV}$ proton linac at the University of Minnesota, ${ }^{5}$ and the second was the PLA at the Rutherford High-Energy Laboratory (RHEL). The PLA produced a proton beam of $50 \mathrm{MeV}$. Both accelerators were built for exploration of nuclear structure in an energy domain not attainable by the cyclotrons of the period, and both were true first-generation DTLs.

A second group of first-generation DTLs were planned for an entirely different purpose. These were to serve as injectors for proton synchrotrons, whose design was just

"Information provided by J. D. Gow, LBL, 1955.

**The $200-\mathrm{MHz}$ frequency originally was set by the chance availability of war-surplus radar amplifiers, but a technology was developed to accommodate this frequency, so that the great majority of the Alvarez DTLs are operated at or very near this value. This is somewhat analogous to the reason the standard US railroad gauge is $4 \mathrm{ft}, 8-1 / 2$ in. By a logical but complicated procedure, it can be shown that this dimension is derived from the distance between the chariot wheels of the Imperial Romans. However, $200 \mathrm{MHz}$ is a reasonable frequency for a proton DTL, even as $4 \mathrm{ft}, 8-1 / 2$ in, is a reasonable gauge for a railroad track. 
being started in the early 1950s. Bcam theorists realized that synclurotrons required beam injection at some intermediate proton energy and that the injected beam must also meet certain stringent requirements with regard to compactness (a property that has since been quantified as "emittance"). Client proton synchrotrons that used DTL injectors included the 6.2-GeV Bevatron at LBL, the 8GeV Nimrod at RHEL, the $10-\mathrm{GeV}$ Synchrotron at ITEP in the USSR, and the 28-GeV Proton Synchrotron (PS) at the then newly established CERN Laboratory near Geneva. With the exception of the latter, none of these injectors exceeded $15 \mathrm{MeV}$ in energy. The first ("Old") CERN PS injector produced protons at $50 \mathrm{MeV}$. In common with its two high-energy cousins, the Minnesota $68-\mathrm{MeV}$ and the 50-MeV PLA at RHEL, it was constructed with three separate if tanks. Multiple rf tanks have (at least until very recently) been a standard design because short individual tanks avoid a problem of longitudinal inhomogeneity in the accelerating electric fields. In accelerator physics jargon, such variations are called "tank tilting," whereas the corrective process is termed "flattening."

All of the above injector DTLs, originally designed as first-generation machines, acquired a second-generation character when strong-focusing magnets were introduced into the drift tubes. In most cases, the magnets were added even before an initial beam was reported. It is especially noteworthy that, just before the prototype 32MeV DTL was shipped from LBL to its final location at the University of Southern California, its drift tubes were fitted with electrostatic strong-focusing electrodes. These focusing devices appear to have worked at least as well as the original focusing grids to produce a useful beam.*

It is important to point out that all the first-generation DTLs were designed without the aid of the modern digital computer. Only analytic solutions, together with if modeling techniques, were available.

A third outgrowth of the Berkeley DTL development is much less well known because its existence was classified information for a long time. This was a project that went under the rubric of "MTA." Its ultimate goal was to produce extremely intense (0.1- to $1.0-A)$ beams of deuterons to create powerful fluxes of neutrons by the stripping process. The neutrons then were to be used to convert fertile elements (such as depleted uranium) into fissiles.

*Information provided by C. N. Waddell, University of Southern California, 1983.
Fissile materials were needed for nuclear weapon production and were at that time believed to be very rare in the US. When the Atomic Energy Commission offered large cash bonuses for discovery of high-grade uranium ores, a number of active uranium prospectors soon proved that this concern was without foundation. The discovery of extensive uranium deposits thus led to the demise of the MTA project in 1955-56. However, this project [which, incidentally, was the reason for the location of the laboratory that was to become Lawrence Livermore National Laboratory (LLNL)] produced two important technical advances that came very close to creating the second generation of DTLs.

The most important of these was the large-scale use of a previously developed process for pressure-cladding steel plate with a thin layer of copper." When large copper-clad steel plates were available, it became possible to produce a cylindrical tank that served both vacuum. and if functions. Such a rigid DTL tank is almost free of thermally induced energy chanzes. It also has a much smaller total surface area ihan a DTL tank built with an If liner, so that the burden on the vacuum pumps is correspondingly reduced.

A second improvement associated with MTA was the elimination of grid focusing. Because strong (quadrupole) focusing was unknown at the time, weak (solenoidal) focusing was installed in the MTA drift tubes. These drift tubes could accommodate the large solenoids required for focusing because they were very large in both prototype MTA DTLs, which were operated at 12.5 and $48.6 \mathrm{MHz}$. These reduced frequencies were employed principally to achieve a duty factor of $100 \%$. The two MTA DTLs were (until 1981) the only DTLs that had ever been operated at $100 \%$ duty factor. Duty-factor limitation is not (in general) caused by the physics of DTL accelerators, but by heat-dissipation problems, particularly those in the rf amplifiers. Strenuous efforts are again being made to provide a $100 \%$ duty factor by rf amplifier redesign. A low power frequency is always helpful in increasing duty factor, and it was the only solution available at that time.

The MTA project produced two DTLs that were said to be "forty years ahead of their time" in technology. Indeed, even the objective of the MTA development (electronuclear fuel breeding) has been revived almost four decades later, although the present objective is for civil, rather than military, use. ${ }^{7}$

*Information provided by W. A. Brobeck, Brobeck Associates, 1983. 
Figure 1 presents historical data on US-based DTLs, each of which is represented by a different bar. The first several generations of DTL are differentiated by characteristic hachures on each bar. Reported development and construction times appear as broken lines to the left of the bar. Location of the DTL is indicated beneath the bar; several have been moved from the site of origin. Modification, terminal energy (to the left of the bar), and additional information (to the right) are also shown. Figure 2 displays the equivalent information for foreign DTL histories.

Most of the historical data for all DTLs were taken from three catalogs of accelerators. ${ }^{8-10}$ It is interesting that three intermediate first/second-generation foreign DTLs-rf-liner construction but rebuilt with strong focusing-still appear to be operational in 1983.

Specifically excluded from Figs. 1 and 2, because of space, are most of the several Wideröe-type DTL accelerators. The principal representatives of this type include the SuperHILAC injector (Fig. 1); the GSI heavy-ion DTL at Darmstadt, West Germany; and the RILAC heavy-ion DTL at Ibaraki, Japan. (The RILAC is especially interesting because it is a tunable DTL.) A number of other Wilderöe DTLs, to be described later, are similarly excluded. Most of them are designed for very low particle velocity $(0.01 \mathrm{MeV} / \mathrm{u})$, which is appropriate for acceleration of heavy ions.*

\section{SECOND-GENERATION DRIFT-TUBE LINACS}

These DTLs have both integral-tank construction and strong focusing but lack some of the refinements that characterize the third generation.

Thu strong-focusing principle, although discovered somer hat earlier, ${ }^{11}$ was first adapted for DTL use in

*Information provided by J. W. Staples, LBL, 1982.

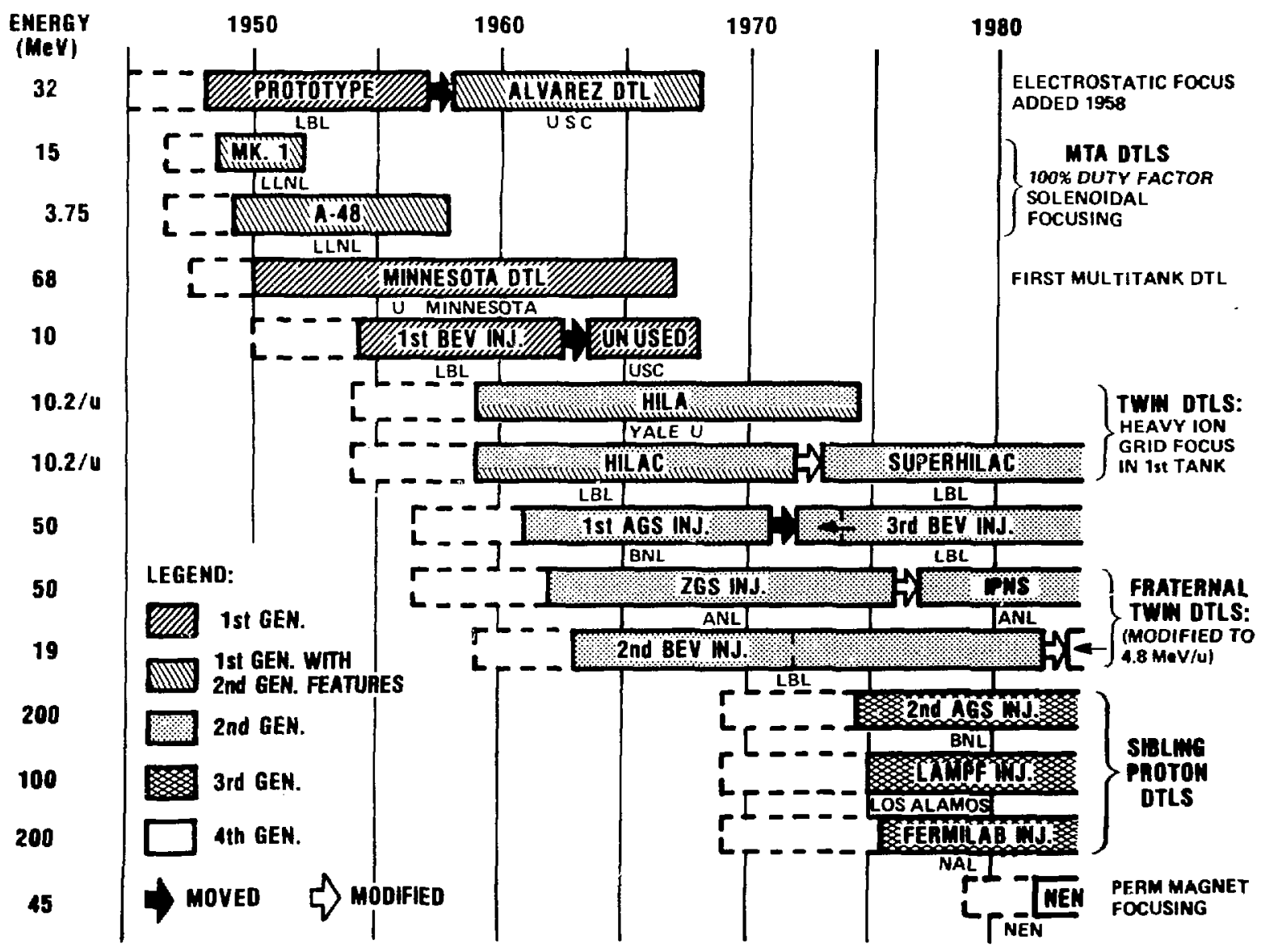

Fig. 1. US DTL histories. 


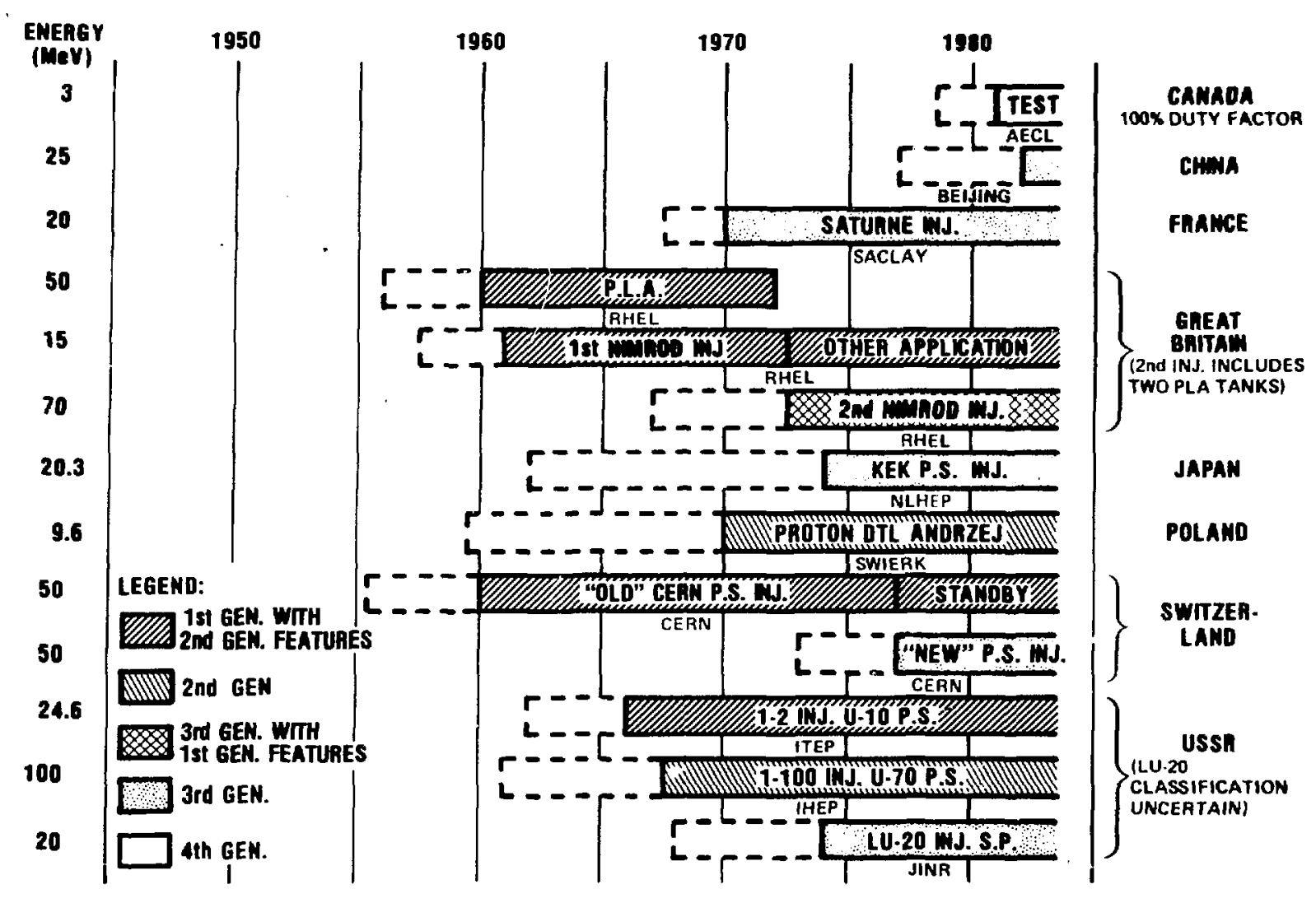

Fig. 2. Foreign DTL histories.

1955. ${ }^{12}$ Its application to the DTL was obvious: both the punishing beam losses caused by the focusing grids and the concomitant radiation hazards were eliminated. Extraction of a large fraction of the injected beam could reasonably be anticipated from such a linac. A large current was particularly important when the DTL served as an injector because the high-energy synchrotrons had a very limited period of time during which an injected beam could be accepted, and it was desirable to have much higher average circulating beams in such synchirotrons than those that could be produced from gridfocused DTLs.

The several advantages of integral-tank construction have been noted already. It was also important that improved sorption-type vacuum pumps had reached a mature state of development at about that time. Better vacua and cleaner surfaces, with reduced spark breakdown, were the result.

A third advance was in the development of if power amplifiers. New models with peak-power capabilities in the few-megawatt range became available, so that in many instances only one amplifier had to be used on a single DTL tank.

The first (quasi) second-generation DTLs actually constructed were designed to accelerate heavy ions rather than protons. These were the Yale HILA and the LBL HILAC, which were jointly designed by an LBL/Yale team in 1953-54 and became operational in 1958-59 (Ref. 13). The two were almost identical, each having two tanks and working at a frequency of $70 \mathrm{MHz}$. The only first-generation feature remaining in these "twin" DTLs was the use of grid focusing in the low-energy or prestripper tank, which produced about $2 \mathrm{MeV} / \mathrm{u}$. This particular design feature was necessitated by the low velocities of the heavy ions and the consequent small size of the pre-stripper drift tubes, in which there was insufficient space for magnet installation. The second, or poststripper, tank was in fact strong focused and produced a final energy of about $10.2 \mathrm{MeV} / \mathrm{u}$. The tanks required very good vacua to minimize the chance of chargechanging collisions with air molecules. The improvements in vacuum pumps and construction are significant in this regard. 
Within a few years, three new injector proton DTLs, all of second-generation construction, were put into service. The if power tube development was a very important factor at that time.* Figure 1 shows that one of these, the old ZGS injector at Argonne National Laboratory (ANL), is still in operation as the injector for the Intense Pulsed Neutron Source (IPNS).** Second-generation DTL construction in Europe appears to have been limited to the I-100 injector for the Serpukhov synchrotron, although it is probable that the $10-\mathrm{MeV}$ "Andrzej" DTL at Swierk, Poland, is also a secondgeneration accelerator. Its classification is inferred from the period during which it was reportedly designed (Fig. 2).

\section{THIRD-GENERATION DRIFT-TUBE LINACS $\dagger$}

The third generation generally is characterized by quantitative changes in precision rather than by qualitative changes, such as the introduction of new types of hardware. Improved computer codes for calculating beam dynamics and rf structures were introduced. One important new third-generation structure concept that requires special mention is the alteration of the DTL structure by means of the postcoupler. This minor modification decreases efficiency (that is, it decreases shunt impedance), but its importance is principally that it can suppress the effects that cause tank tilting, so that longer rf tanks can be used. Three new third-generation DTLs were built in the US in the late 1960-early 1970 time frame. One was an injector of increased energy (200 $\mathrm{MeV}$ ) for the AGS at BNL, which initiated a trend toward increase of injection energy at other synchrotrons. The upgraded BNL injector was one product of a joint design effort among BNL, the National Accelerator Laboratory (Fermilab), and the LAMPF designers at Los Alamos. Los Alamos required a DTL of only $100 \mathrm{MeV}$ as the injector into the side-coupled-cavity structure of LAMPF. The latter structure provides the balance of the

"Information provided by P. Grand, Brookhaven National Laboratory (BNL), 1983.

**Information provided by V. Stipp, ANL, 1983.

†The important distinctions between second- and third-generation DTLs were explicitly pointed out by both P. Grand of BNL and D. A. Swenson of Los Alamos. energy gain up to $800 \mathrm{MeV}$.* There are some structural differences among these three designs, but they are at least "sibling" DTLs."*

At the same time as the increase of injection energies in the US, both the CERN PS and Nimrod at RHEL received new injectors. Only the Nimrod injector represents an energy upgrade. (Interestingly, this new injector consists, in part, of two old PLA tanks with rf liners and thus preserves some first-generation features.) The "New" CERN PS injector is a true third-generation DTL that has the same energy as the "Old" PS injector. In the meantime, staff at the new French SATURNE synchrotron had constructed a $20-\mathrm{MeV}$ injector, as had the Japanese National Laboratory for High Energy Physics, for injection into the KEK proton synchrotron. There is also one report about a similar new injector for the Dubna Synchrophasotron, but little information has been obtained about this DTL. ${ }^{9}$ These are all, presumably, third-generation DTLs. There was also a DTL started at Beijing, China, as an injector for a synchrotron whose construction is now said to have been deferred or cancelled. ${ }^{*}$ This DTL has achieved about $25 \mathrm{MeV}$ energy and is now in use for radiochemical research.

An important change in research emphasis at LBL led to a need for heavy-ion injection into the Bevatron synchrotron. As a result, the HILAC was replaced by a severely modified drift-tube structure, which had multiple rf tanks, one of which is a Wideröe-type multitank. This DTL is called the SuperHILAC and is now use 1 for Bevatron injection. (The combination of the two is known as the "Bevalac.") A significant innovation in the SuperHILAC is that it is cryopumped at liquid-helium temperatures-the issue of gas stripping of heavy ions remains important-but SuperHILAC is not operated with superconducting cavities, as the name might suggest. + Subsequent changes in the Bevatron vacuum structure have since made it inadvisable to accelerate protons, which is why the old AGS injector is no longer used. $+\dagger$

*Expert opinion differs as to whether the side-coupled-cavity linac is a DTL or something else. The author prefers to dodge this controversy at present, hoping that accelerator taxonomists eventually will agree.

**Information provided by P. Grand, BNL, 1983.

†Information provided by J. Selph, LBL, 1983.

† Information provided by J. W. Staples, LBL, 1983. 


\section{PRESENT STATUS}

The status of development of any subtechnology can be evaluated in a number of ways. Some of the questions that can properly be raised are listed below.

- How reliable are the systems that have, to date, been produced?

- What has been the level of capital investment?

- How many persons have been employed in this subtechnology, what are their origins and interests, and are any of the personnel numbers changing?

The first question can be readily answered by referring to Figs. 1 and 2. Within the US alone, more than 75 machine-years of operation of second- and third-generation DTLs are represented. Where it has been recorded, the reliability of the proton accelerators is greater than $90 \%$. Heavy-ion DTLs tend to have a lower reliability (about $70 \%$ ), but principally this is caused by the difficulties associated with required changes of particle from the ion source.* A similar experience with reliability of foreign DTLs is suggested from the data presented in Fig. 2. The two oldest of these (the Nimrod and CERN PS injectors) have collectively logged almost 50 machineyears between them and are still working. Less information is available on the Russian DTLs, although the supervisor of one has claimed a reliability of $98 \%$ or better. ${ }^{9}$ Indeed, the author can add a personal recollection to substantiate such apparently extravagant claims for DTL reliability. In 1954-55, the prototype $32-\mathrm{MeV}$ Berkeley DTL had a reliability factor of about $75-85 \%$. This was because the horizontal 4-MeV Van de Graaff accelerator, used for injection to this DTL, was likely to lose a charging belt to spark damage about once every four weeks, and it took almost one week to repair the Van de Graaff." There was never any serious difficulty with the DTL itself.

The question of the level of capital investment is more difficult to answer accurately. In the earliest stages of DTL development, much valuable war-surplus if equipment was used, and it is now virtually impossible to determine the actual value of such material. Second, very little effort was made to do careful cost accounting for projects before about 1955; therefore, the true amount spent on research and development during this period is

*Information provided by J. Selph, LBL, 1983.

**Information provided by R. D. Watt, Stanford Linear Accelerator Center (SLAC), 1983. almost certainly irretrievable. Third, the effect of inflation on the reported cost figure, even if the latter is known, is a moot question. Price increases in food, housing, or automobiles siin be determined with reasonable precision, but $D^{\prime}$ 'LLs do not enter significantly into the cost-of-living index.

However, for a rough cost estimate (both at the time of construction and also in 1983 dollars), a tabulation has been prepared for the last nine major DTLs built at national laboratories in the US. This tabulation, as can be seen from Fig. 1, includes all second- and third-generation machines. In all instances, it has been possible to obtain an estimate of the cost in contemporary dollars, either from an official record or from a sufficiently expert source. (One entry in the cost column, for the second Bevatron injector, had to be interpolated.) These estimates appear in Table I and are given in dollars for the year of completion. For proration to 1983 dollars, the Los Alamos Building Construction Index (LABCI) inflation factors were used.** These inflation factors are strictly applicable only to industrial buildings, but it can be argued that such building costs must be very similar to those of accelerators. Both types of construction are highly labor-intensive, and many of the same materials are used: steel, copper, plumbing supplies, electrical equipment, and concrete. An attempt was made in Table I to exclude costs other than those directly chargeable to the construction of the accelerators themselves. All irrelevant accelerator costs have been deleted from the Table I. For example, only the cost of the 100-MeV Alvarez DTL section of LAMPF has been included.

The computation shown in Table I suggests that almost a quarter of a billion 1983 dollars was spent on DTLs within the US alone since the middle 1950s. When the unknown figures for first-generation DTL development are estimated, it appears a sum that is closer to half a billion 1983 dollars is a more reasonable estimate. If one were also to attempt to include the dollar value of the technology transfer from electron linac technology (which has surely received three to five times as much funding as has the DTL over the same period), the capital investment value must rise to a still higher figure.

\footnotetext{
*Information provided by L. W. Alvarez, LBL, 1983.

* The Los Alamos Building Construction Index is derived from the Engineering News Record before 1970 and from Data Research Corporation work since 1970 . These inflation figures were kindly provided by G. D. Lemon of ENG-8, Les Alamos National Laboratory.
} 
TABLE I. Estimated Original Costs and 1983 Prorated Original Costs of Nine Second- and ThirdGeneration US DTLS

\begin{tabular}{|c|c|c|c|c|c|c|}
\hline Linac & Location & $\begin{array}{l}\text { Energy } \\
(\mathrm{MeV})\end{array}$ & $\begin{array}{c}\text { Year } \\
\text { (Completed) }\end{array}$ & $\begin{array}{l}\text { Original } \\
\text { Cost } \\
\text { (Est. \$M) }\end{array}$ & $\begin{array}{c}\text { 1983 } \\
\text { Prorate } \\
\text { Factor }\end{array}$ & $\begin{array}{c}1983 \\
\text { Cost } \\
\text { (Est. \$M) }\end{array}$ \\
\hline HILA & Yale & $10.2 / \mathrm{u}$ & 1959 & $7.5^{\mathrm{b}}$ & 5.48 & 41.1 \\
\hline HILAC & LBL & $10.2 / \mathrm{u}$ & 1959 & $10.0^{\mathrm{b}}$ & 5.48 & 54.8 \\
\hline $\begin{array}{c}\text { Ist AGS } \\
\text { Inj. }\end{array}$ & BNL & 50 & 1961 & $5.0^{\mathrm{c}}$ & 4.97 & 24.8 \\
\hline ZGS Inj. & ANL & 50 & 1962 & $5.0^{d}$ & 4.82 & 24.1 \\
\hline $\begin{array}{l}\text { 2nd BEV } \\
\text { Inj. }\end{array}$ & LBL & 19 & 1963 & $2.0^{e}$ & 4.68 & 9.4 \\
\hline $\begin{array}{c}\text { 2nd AGS } \\
\text { Inj. }\end{array}$ & BNL & 200 & 1970 & $10.0^{f}$ & 3.21 & 32.1 \\
\hline $\begin{array}{c}\text { LAMPF } \\
\text { (DTL } \\
\text { only) }\end{array}$ & Los Alamos & 100 & 1970 & $6.0^{f}$ & 3.21 & 19.3 \\
\hline $\begin{array}{l}\text { Fermilab } \\
\text { Inj. }\end{array}$ & Fermilab & 200 & 1971 & $10.0^{r}$ & 2.95 & 29.5 \\
\hline \multirow{2}{*}{$\begin{array}{l}\text { Super- } \\
\text { HILAC }\end{array}$} & LBL & $8 / u$ & 1972 & $1.5^{8}$ & 2.72 & 4.1 \\
\hline & & & Total, Original & $57.0 \mathrm{sM}$ & Total, 1983 & $239.2 \mathrm{SM}$ \\
\hline \multicolumn{7}{|c|}{$\begin{array}{l}\text { aInformation provided by G. D. Lemon, Los Alamos, } 1983 . \\
\text { 'Estimates from G. W. Wheeler, Temple University, } 1983 . \\
\text { 'Estimated from similarity in size to ZGS injector. } \\
\text { dReported: } 1976 \text { Compendium of Linear Accelerators. Atomic Energy of Canada, Ltd., AECL-5613 (Ref. 9). } \\
\text { 'Estimated as being } 40 \% \text { as expensive as ZGS injector, from size. } \\
\text { 'Estimates from P. Grand, BNL, } 1983 \text {. } \\
\text { BEstimated by J. Selph, LEL, 1983. }\end{array}$} \\
\hline
\end{tabular}

Attention is next given to the number of workers in the DTL subtechnology. The problem of selecting a credible database for this determination again arises. In every odd-numbered year since 1965, the IEEE, acting together with the American Physical Society, the Department of Energy (or its predecessors, ERDA and AEC), and the National Science Foundation, has sponsored a Particle Accelerator Conference. A completely different kind of conference has also been held in recent even-numbered years at North Texas State University in Denton, Texas. The Denton conferences are subtitled "Applications of Accelerators in Research and Industry" and have numerous industrial sponsors, as well as most of the professional and Federal sponsors previously mentioned. Then, there is a series of "International Conferences on
High-Energy Accelerators," which have often been held in Europe. The IEEE and Denton conferences all tend to have large attendances-the last IEEE conference in Santa Fe, New Mexico, had almost 1000 attendees-and, with the International Conferences, serve as important forums for experts in the DTL technology field. They have, of course, also included experts in the design of many other types of accelerators, and for this reasin, they may provide inapplicable data about the development of the DTL.

For the present analysis, it is therefore probably more informative to examine the attendance and presentation records at a more restricted and specialized series of conferences. Since their origin, these conferences have been devoted almost exclusively to linear accelerators. In 
fact, for several years, the DTL was the only particle lincar accelerator discussed at these conferences. This exclusiveness was formally abandoned in 1976; since then, electron-accelerator presentations have not only been included, but have been welcomed.

Eleven such linear accelerator conferences have been held since 1961. They have always been hosted by a single national laboratory or university, and attendance has usually been by invitation only. This restricts the number of participants but ensures that personal exchanges are facilitated. Four linac conferences have been hosted by BNL (1961, 1962, 1968, and 1970); three by Los Alamos (1966, 1972, and 1981); and one each by Yale University (1963), Midwest University Research Association (MURA) (1964), Fermilab (1979), and Chalk River, Canada (1976).* Conference attendance and other information were derived from the conference reports.

Figure 3 shows the attendance at these linac conferences and analyzes the attendance by country of origin, and Fig. 4 analyzes it by professional affiliation. The data in Fig. 3 indicate that North Americans dominate conferences held in North Amcrica. However, the "foreign" attendance at the linac conference has remained surprisingly constant since about 1966 . A rather unexpected datum appears in Fig. 4. The number of participants from national laboratories (from all nations) has shown an extraordinary fluctuation, and perhaps this reflects the state of the world and national economies as well as any other index. The number of government participants has been small but about constant. The count of university attendees, once major contributors to DTL technology, has remained about the same or perhaps has even declined somewhat at recent conferences. In contrast, the number of industrial personnel, whose attendance at the early conferences was miniscule, has shown a rapid growth during the last few years. In 1979, industry attendance natched that of the academic contingent, whereas in 1981, people from industry conspicuously outnumbered academics. These data on industrial participation alone suggest that the DTL technology is well out of the experimental stage.

For completeness, the number of papers at each of these linac conferences, together with the mode of presentation, is shown in Fig. 5. The effective saturation observed in the number of allowed papers probably demonstrates a prudent decision by various conference

*The 1984 Linac Conference was held at Darmstadt, West Germany, the first outside North America. organizers that 80 to 100 papers are about all that can be presented meaningfully in the course of a 3- or 4-day meeting.

All the above inforrnation suggests that DTL technology has reached a level of high maturity in the almost 40 years since it began. But, as in the case of all technologies, advancement is possible, and the final section of this report will assess several recent developments that are expected to appear in the fourth generation of the DTL and in the generations beyond.

\section{PEOJECTION: THE FUTURE}

The community of scientists and engineers who have brought the DTL to its present level of development has made much progress in designing and testing the concepts and components that will be incorporated into the next several generations of DTLs. The most significant contributions since 1979 have been

- the radio-frequency quadrupole (RFQ) injector,

- permanent-magnet focusing, and

- $100 \%$ duty-factor operation.

However, the following developments, although of somewhat earlier origin, have demonstrated their value within the last 6 or 7 years:

- computer control of accelerator operation,

- electroplating DTL structures to suppress electrical breakdown, and

- superconducting structures.

Some comments about each of these developments are in order. The evolution of the RFQ has almost certainly been the most important advance. When the retention of grid focusing in the first two heavy-ion linacs was discussed, it was remarked that grids were required because the velocity of heavy-ion injection was very low. In fact, all existing DTLs have been designed to be injected at an energy/velocity that is somewhat low for efficient operation. Injection energy is usually $750 \mathrm{keV}$, which is about the maximum that can be reliably produced by a Cockcroft-Walton injector." At such low velocities, the DTL is not really an efficient accelerating

*The prototype Alvarez 32-MeV DTL was injected by a 4$\mathrm{MeV}$ Van de Graaff. This injection energy was established on the premise that the radial focusing would be done by the thin beryllium foils, which turned out to have no useful lifetime. Thus, the first DTL avoided the low-velocity problem, although the reason it was able to do so was based on an invalid assumption. 


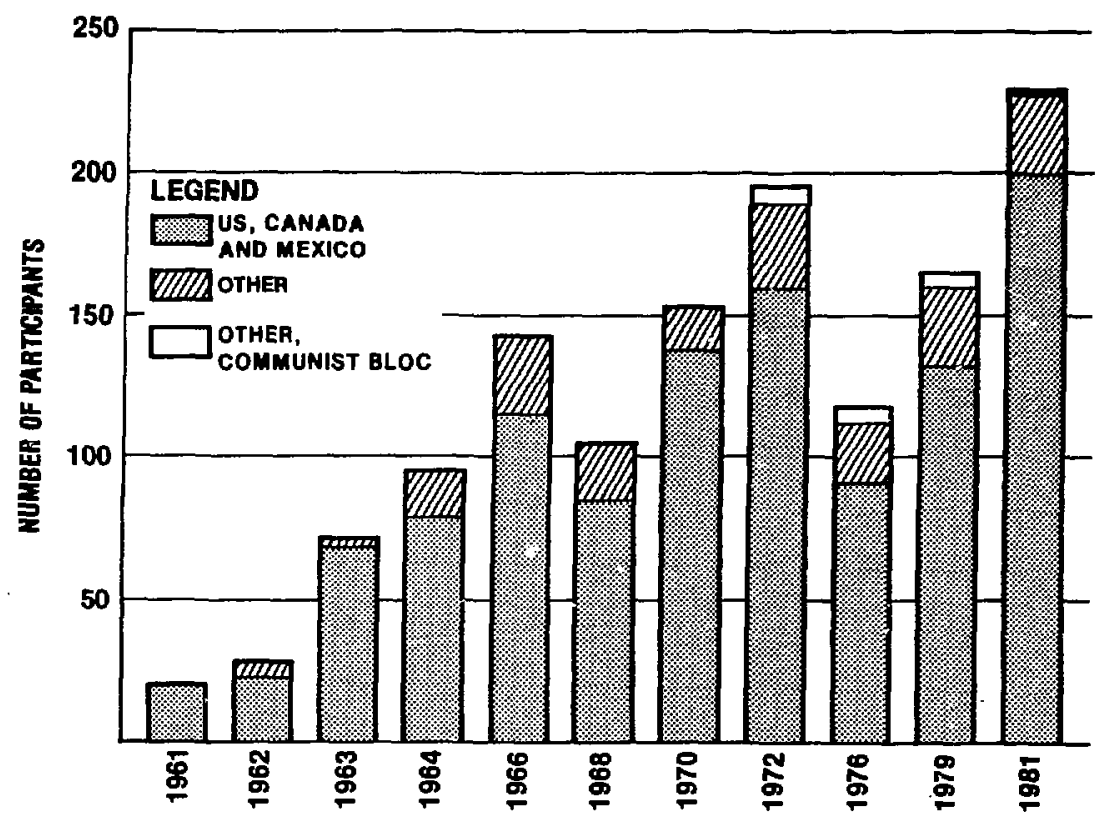

Fig. 3. Linear Accelerator Conference participants by nationality.

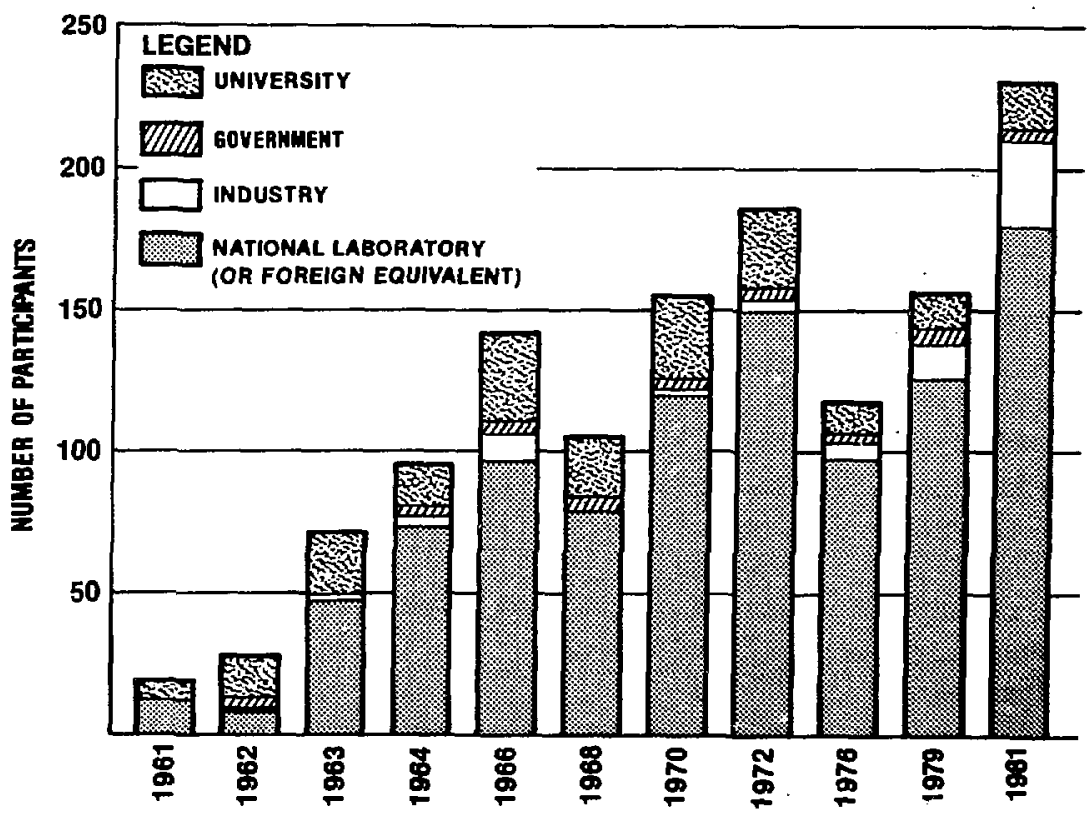

Fig. 4. Linear Accelerator Conference participants by affiliation. 


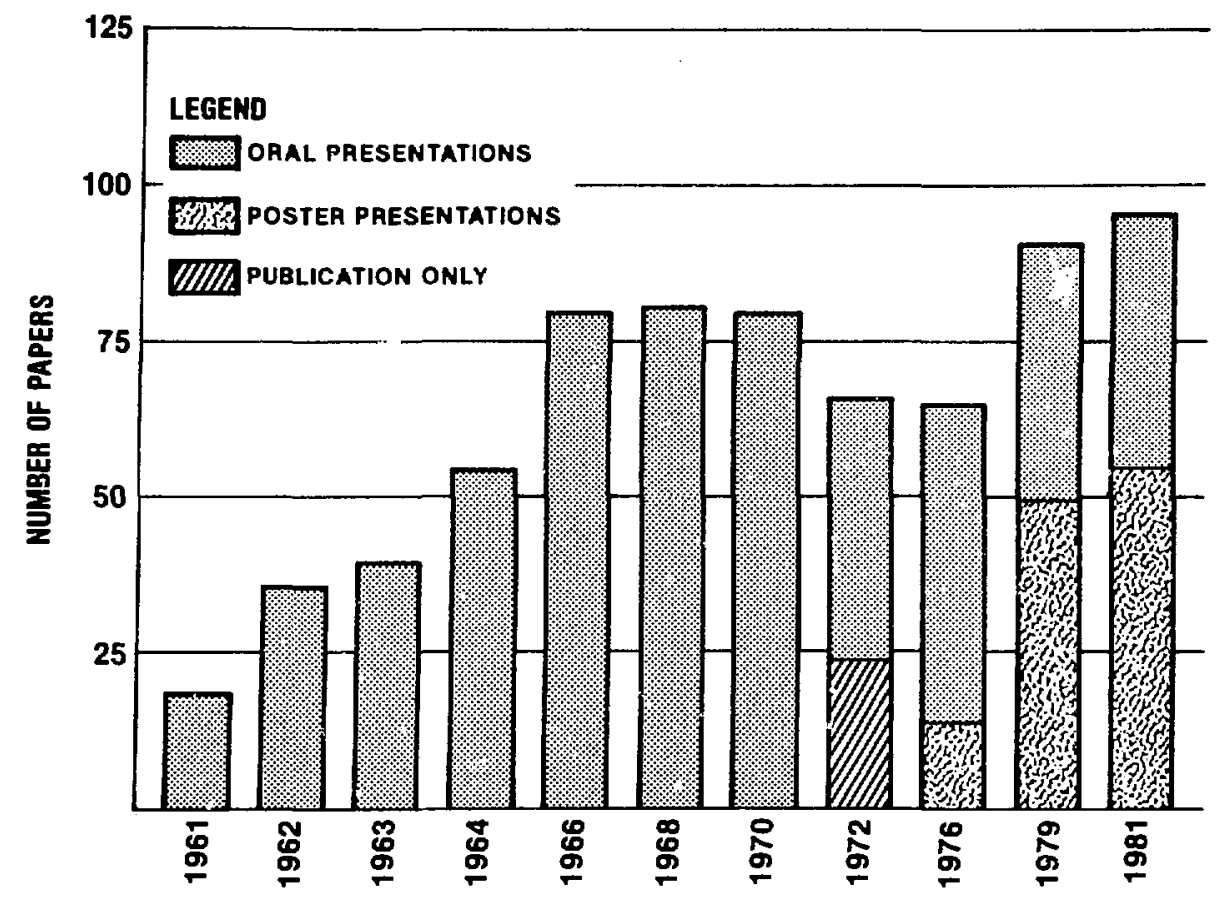

Fig. 5. Linear Accelerator Conference papers.

Conference participant and paper presentation data were derived from these publications:

1961: BNL-5532

1962: BNL-6511

1963: TID-7691

1964: MURA-714

1966: LA-3609

1968: BNL-56120

Most of these are available from the DOE Technical Information Center, P.O. Box 62, Oak Ridge, TN 27831.
1970: CONF-700929

1972: LA-5115

1976: AECL-5677

1979: BNL-51134

1981: LA-9234-C structure. $^{14}$ Moreover, it is extremely difficult to insert strong-focusing magnets of adequate strength inside the low-velocity drift tubes because of space limitations. What had been needed was a compact preaccelerator that bunched the injected beam in longitudinal phase space (to prepare it for injection into the DTL "phase bucket"), accelerated it to $\sim 2 \mathrm{MeV}$, and restricted emittance growth of an intense beam, all at the same time.

The RFQ, originally proposed by Kapchinskii and Teplyakov in 1970 , appears to have met all of the above specifications. ${ }^{13}$ It has produced a proton beam with an average current of almost $100 \mathrm{~mA}$, with low beamemittance growth, and has achieved an output energy of
$2.0 \mathrm{MeV} .^{16}$ The beam also is properly bunched for injection into a DTL. The RFQ is now either in use or under construction for DTL accelerators at no fewer than 12 laboratories, both in the US and abroad. It is anticipated that most working DTL installations will be retrofitted with an RFQ within the next few years. The RFQ clearly is an important advance and a hallmark of the fourth-generation DTL.

Permanent-magnet focusing has resulted from the recent development of several exceptionally powerful permanent-magnet materials, one of which is a samarium-cobalt alloy. Their properties have been ingeniously utilized in new magnet designs by Halbach. ${ }^{17}$ 
One new DTL, designed and built by the New England Nuclear Corporation, has achieved $45 \mathrm{MeV}$ of proton energy and 500-mA beam intensity but uses only permanent-magnet focusing. * In those future DTL installations in which quadrupole-magnet fields do not require adjustment, permanent-magnet focusing almost certainly will be the conventional technology. Use of this feature also will identify a fourth-generation DTL.

Until 1981, 100\% duty-factor operation (continuouswave operation) had not been attempted since the MTA project. A basic limitation has always been the difficulty of heat rejection from the if amplifiers, although there are some additional problems. Investigators in the USSR have reported successful operation of a 1-MW amplifier at $100 \%$ duty factor.** This is the Gyrocon, one model of which has been built at Los Alamos. Recently, the commercial firm of Thompson-CFF produced a $100 \%$ duty-factor klystron that operates at about $400 \mathrm{MHz}$ (this amplifier was specifically designed for accelerator use). Two projected DTL accelerators, which are planned to operate at $100 \%$ duty factor, are the FMIT project at Los Alamos and the ZEBRA project at Chalk River. ${ }^{7}$ FMIT is planned for the production of intense neutron fluxes to investigate material stability under conditions that might occur near a controlled thermonuclear reactor, whereas ZEBRA is an interesting revival of the electronuclear fuel-breeding concept. Its purpose is the production of fissiles for reactor fuel from existing unused fertile material, as an alternative to the breeder reactor. The Chalk River group has operated an Alvarez-type DTL at $3-\mathrm{MeV}$ proton energy and $100 \%$ duty factor since $1981 .^{18}$

The universal applicability of high duty-factor operation to all DTLs is not obvious. In situations where an intense beam is needed, it is very desirable. If DTLs were still being built exclusively for nuclear-structure experiments, most users would indeed prefer a $100 \%$ duty factor because of electronic counting limitations. However, it appears that LAMPF is the only major DTL installation devoted to fundamental research of this type; thus, it probably would be the only DTL installation to profit from an increased duty cycle. At energies below 20 to $30 \mathrm{MeV}$, the tandem Van de Graaff accelerator has pre-empted the field of nuclear-structure investigation, even as the azimuthally-varying-field cyclotron has done

*First operation of the NEN DTL was informally announced at the 1981 Linear Accelerator Conference.

* Information provided by P. J. Tallerico, Los Alamos National Laboratory, 1983. at higher energies. Both of these have large duty factors. ' For injector applications, there is no obvious advantage in increasing the duty factor of the DTL injector beyond that in which injection can be done, unless the injector serves a dual purpose, as is the situation with both the AGS injector and the injector used at Fermilab. The $100 \%$ duty-factor DTLs appear to have limited application.

Computer control of accelerator operation was first introduced on a large scale at LAMPF and has definitively established its value. It is, of course, not limited to DTL use, but it can be particularly useful in any linear machine because occasional vagaries of the beam can be quickly located and promptly corrected.

Electroplate finishing of components was first done successiully on the PIGMI test accelerator at Los Alamos (although it had been tried earlier at KEK). Because it made a high electric field possible, it will almost certainly be employed in the fabrication of future DTLs.

Finally, there is superconductivity to consider. Although it may not have universal utility, it could become increasingly important as the cost of electric power increases. There are other advantages that may also accrue in terms of stability control. All superconducing accelerators descend (at least in principle) from the successful starding-wave electron linac that was operated for many years at Stanford University, under the direction of A. Schwettman. In the US, the principal technology application of superconducting phenomena to DTL design has been the construction of "afterburners" to increase the energy of a heavy-ion beam after it has been emitted from a tandem Van de Graaff accelerator. (These DTLs are of the Wilderöe type.) The objective of the energy augmentation is extension of the exploration of nuclear structure with heavy ions, and for this reason, beams of high intensity are not needed. Three such projects in the US are in various stages of completion.* At ANL, a superconducting DTL afterburner has been in at least partial operation for almost 5 years. The superconductor used at. ANL is niobium.** The tandem at SUNY, Stony Brook, has had a similar DTL structure in operation for several months with lead used in the cavity construction instead of niobium. $\uparrow$ The latest member of this special group of superconducting heavy-ion accelerators will be a niobium-fabricated afterburner to be

\footnotetext{
*Times are given as of mid-1983.

**Information provided by L. M. Bollinger, Fermilab, 1983. †Information provided by P. Paul, SUNY, Stony Brook, 1983.
} 
built at the University of Washington with an electromechanical structure based on a slightly different concept from that of the other two.* After a few years, there should be sufficient experience to evaluate which of the various designs and materials might be most suitable for the proton DTL. We do not expect a general use of the superconducting technology at this time, but in a few applications, superconductivity will be invaluable.

\section{ACKNOWLEDGMENTS}

The author would like to express special gratitude to H. O. Dogliani, AT Division, and J. A. Farrell, Group AT-2, Los Alamos National Laboratory, for the invitation to work on this project and to extend sincere thanks to R. A. Jameson, R. K. Cooper, D. A. Swenson, and G. A. Sawyer, also of AT Division, for their gracious assistance in collecting necessary data. In addition, the following people have all provided much useful information and deserve mention for their unusual cooperation and help: G. W. Wheeler of Temple University;** S. Ohnuma, P. V. Livdahl, and C. D. Curtis of Fermilab; L. Smith and J. Selph of LBL; V. Stipp and L. M. Bollinger of Fermilab; P. Paul of SUNY, Stony Brook; W. A. Weitkamp of the University of Washington; C. N. Waddell of the University of Southern California; and L. E. Johnston of the University of Idaho.

The author wishes to acknowledge his particular indebtedness to Pierre Grand of BNL, whose detailed knowledge of recent DTL history has been invaluable, and to John W. Staples of LBL, whose information on historical and technical matters relating to DTL operation and design has assisted immeasurably in the preparation of this review. Very special thanks are due to $L$. W. Alvarez to LBL, whose familiarity with all aspects of DTL technology is necessarily unique and whose preliminary review of the present document assisted the author in avoiding many significant inaccuracies. Any that remain are, of course, the sole responsibility of the author.

*Information provided by W. A. Weitkamp, Nuclear Physics Laboratory, University of Washington, 1983.

**Present address: Office of Provost, University of Tennessee.

\section{References}

1. R. Wideröe, Archiv. f. Electrotechnik 21, 387 (1928).

2. Luis W. Alvarez, Hugh Bradner, Hayden Gordon, Chaim Richman, Wolfgang K. H. Panofsky, and John R. Woodyard, "Berkeley Proton Linear Accelerator," University of California Radiation Laboratory report UCRL-236 (November 1948); L. W. Alvarez, Hugh Bradner, Jack V. Franck, Hayden Gordon, J. Donald Gow, Lauriston C. Marshall, et al., Rev. Sci. Instrum. 26, 111 (1955).

3. J. C. Slater, Rev. Mod. Phys. 20, 473 (1948).

4. H. B. Knowles, Rev. Sci. Instrum. 29, 130 (1958).

5. E. A. Day, R. P. Featherstone, L. H. Johnston, E. E. Lampi, E. B. Tucker, and J. H. Williams, Rev. Sci. Instrum. 29, 457 (1958).

6. P. V. Livdahl, "The Livermore MTA Project and Its Influence on Modern Linacs," in "Proceedings of the 1981 Linear Accelerator Conference," Los Alamos National Laboratory report LA-9234-C (February 1982), p. 5.

7. S. O. Schriber, "The Zebra (Zero Energy Breeder Accelerator) Program at CRNL mA-10 MeV Proton Linac," in "Proceedings of the 1981 Linear Accelerator Conference," Los Alamos National Laboratory report LA-9234-C (February 1982), p. 363.

8. G. E. Fischer and R. T. Nelson, "Catalog of HighEnergy Accelerators," Stanford Linac Accelerator Center publication SLAC-173 (May 1974).

9. J. S. Fraser and S. O. Schriber, "Compendium of Linear Accelerators-1976," Atomic Energy of Canada, Ltd., publication AECL-5613 (September 1976).

10. J. H. B. Masden and P. H. Standley, "Catalog of High-Energy Accelerators," CERN publication, XI International Conference on High-Energy Accelerators (1980). 
11. E. D. Courant, M. S. Livingston, and H. Snyder, Phys. Rev. 88, 1190 (1952).

12. L. Smith and R. L. Gluckstern, Rev. Sci. Instrum. 26, 220 (1955).

13. E. L. Hubbard, W. R. Baker, K. W. Ehlers, H. S. Gordon, R. M. Main, N. J. Norris, et al., Rev. Sci. Instrum. 32, 621 (1961).

14. G. Dôme, Linear Accelerators, P. M. Lapostelle and A. L. Septier, Eds. (North-Holland, Amsterdam, 1970), Sec. 1.1e. Figures 57 and 58 show a maximum in effective shunt impedance at about $18-\mathrm{MeV}$ proton energy for the post-coupled Alvarez DTL. The effective shunt impedance goes essentially to zero for $\beta=0$.
15. I. M. Kapchinskii and V. A. Teplyakov, Prib. Tekh. Eksp. No. 2, 322 (1970).

16. K. R. Crandall, R. H. Stokes, and T. P. Wangler, "RF Quadrupole Beam Dynamics Design Studiss," in "Proceedings of the 1979 Linear Accelerator Conference," Brookhaven National Laboratory report BNL-51134 (September 1979), p. 205.

17. K. Halbach, Nucl. Instrum. Methods 169, 1 (1980).

18. J. Ungrin, J. C. Brown, B. G. Chidley, R. M. Hutcheon, G. E, McMichael, and S. O. Schriber, "Low Energy 100\% Duty Factor Alvarez Linacs at Chalk River," in "Proceedings of the 1981 Linear Accelerator Conference," Los Alamos National Laboratory report LA-9234-C (February 1982), p. 12. 